\title{
Personalised Content in Mobile Applications and Purchase Intentions: An Exploratory Study
}

\author{
Kleopatra Konstantoulaki ${ }^{1}$, Ioannis Rizomyliotis ${ }^{2}$, Antigoni Papangelopoulou ${ }^{2}$ \\ ${ }^{1}$ University of Westminster, London, UK \\ ${ }^{2}$ University of Brighton, Brighton, UK \\ Correspondence: Ioannis Rizomyliotis, University of Brighton, Mithras House, Lewes Road, BN2 4AT, Brighton, UK. \\ E-mail: i.rizomyliotis@ brighton.ac.uk
}

Received: March 26, 2019

doi:10.11114/bms.v5i4.4571
Accepted: October 1, 2019

Online Published: October 17, 2019

URL: https://doi.org/10.11114/bms.v5i4.4571

\begin{abstract}
This study aims to examine how personalised content affects consumers' purchase intentions in the mobile beauty shopping applications within the UK. Based on previous studies personalised content on mobile beauty applications influences consumer behaviour in terms of mobile application convenience, m-loyalty and emotions. In-depth semi-structured interviews were conducted with 12 females between the ages of 18-35 who live in the UK. According to the results, personalised content has a positive influence on both mobile convenience and m-loyalty while for emotions the influence is both positive and negative. Moreover, findings also suggested that the personalisation-privacy paradox can prevent consumers from making a purchase. The study provides suggestions towards m-retailers and managers in relation to m-commerce and beauty mobile applications. Findings also offer an insight with regards to how m-retailers can successfully incorporate personalised content to increase consumers' retention and eventually their profitability.
\end{abstract}

\section{Introduction}

The worldwide expansion of mobile phones and mobile applications, which are nowadays referred to as "mobile apps", has formed a new path of opportunities for marketing trends to target users "on-the-go" (Kim et al, 2013). Consumers that use smartphone devices are expected to reach 5.5billion in 2020 (WARC, 2017) and they are more eager than ever to use m-commerce for purchase (2017). Mobile applications constitute part of the m-commerce's evolution (Mahatanankoon et al, 2005). They are described as software which users can download on their mobile phones (Bellman et al, 2011). For marketers, mobile applications are an innovative marketing tool to build stronger brand identity (Bellman et al,2011). Varnali and Toker (2010, p.144) state that 'the mobile channel has morphed into an ultimate marketing vehicle'. Mobiles have changed the world of retailing by allowing consumers' purchase independently of their time and/or location (Shankar and Balasubramanian 2008).

Nowadays, companies can approach consumers anytime and anywhere through the mobile applications because they are an essential part of their daily lives with the time spent on them to be constantly increasing and it is also considered consumer-friendly approach (Shankar et al, 2010; Kim et al, 2013). The rise of smartphone users in combination with their engagement with the m-commerce, compelled marketers to pay closer attention on their strategies towards mobile applications (Shankar et al, 2016; Ono et al, 2012). More precisely, a great part of retailers' budget, now, is being spent on mobile marketing to improve users shopping experience on the applications (WARC, 2015). Cosmetics industry is considered as one of the fastest growing industries worldwide and their market share is calculated to multibillion-dollars (Hosany and Martin, 2015) and one of the main industry which has embraced digital technology for today's consumers.

The rise of new technologies has replaced the traditional marketing channels for the cosmetics industry which led to sharp growth via the use of m-marketing (Du Plessis, 2017). The use of mobile applications on cosmetics industries is rising rapidly (Du Plessis, 2017). Their goal is to reach new demographics and create an enjoyable and easy to use shopping experience to facilitate their purchases and thus increase their profits (Szutowski and Szułczyńska, 2017). This experience can be defined as a value delivered on a real-time and a precise context (Kumar, 2005). Cosmetics are integrating mobile applications not only to please their current and loyal customers but attract new ones as well (Du Plessis, 2017). 
Nonetheless, even though consumers' willingness to download mobile applications has increased, 50\% of these are deleted within a short period of time (Linton and Kwortnink, 2015). Therefore, there is an immediate need for $\mathrm{m}$-retailers, in order to survive the strong competition, to implement a strategy which will increase consumers' retention and eventually their profitability. For that reason, innovative marketers have incorporated personalised content on their mobile applications ((Parise, Guinan and Kafka, 2016; Adolphs and Winkelmann, 2010). Personalisation offers consumers goods and services which correspond to their personal preferences (Montgomery and Smith, 2009). Personalised content creates a customer-tailored shopping experience through the provision of personalised recommendations, offers and discounts, design and transactions as well as interactive experience (Miceli et al, 2007; Pappas et al, 2014).

Personalised content is an innovative strategy which could result in profitability, however, to be implemented correctly it is important to understand its role on consumer's behaviour and their purchase intentions. The rapid evolution of mobile applications and their functions in terms of innovation and accessibility have transformed consumers' behavioural attitudes on how they experience and use mobile applications as well as their purchase (Shankar et al, 2016). Based on extensive research, the most related variables on consumer behaviour that personalised content affects are m-convenience, m-loyalty and emotions. Enhancing these variables through the use of personalised content, research shows that consumers' purchase intentions are increasing as well. The examination of the role and the effect of personalised content on these variables and, as a result, consumers' purchase is vital for the m-commerce environment as our world is living and evolving in a digital era. M- commerce has been studied the last decades. A moderate pool of studies has been conducted on personalisation and its role on consumer behaviour as well as on its role on purchase intentions. Nonetheless, focusing on cosmetics in the mobile world will contribute to filling any possible knowledge gaps.

The aim of this study is to examine how personalised content affects consumers behavior, purchase intentions in paeticular in the mobile beauty shopping applications within the UK. The study aspires to gain a deeper insight on the influence of personalised content the behaviour of consumers who are already aware of mobile beauty applications with personalised content and analyse its influence on these consumers' purchase patterns.

\section{Literature Review}

\subsection{Personalisation and Mobile Shopping Convenience}

Copeland (1923) was the first to introduce the term of convenience in the marketing literature by highlighting the value of immediacy and eased accessibility of the goods in a store which facilitate purchases. Ahuja and Khazanchi (2016: pp. 612-613) further elaborated its definition and described it as "Ease of usage of tool, which enhances the daily activities of individuals and allows them to easily complete a shopping task, saving time and energy which is required for the shopping process". Berry et al. (2002) stated that service is also fundamental for the consumers' perception of convenience. In essence, shopping convenience is closely linked with the time and the physical, cognitive and psychological effort consumers invest in their shopping (Jiang, Yang and Jun, 2013; Berry et al, 2012).

Shopping convenience constitutes one of the key triggers for consumers to choose mobile shopping (Beauchamp and Ponder, 2010; Colwell et al, 2008). Today's customers tend to spend less time on physical stores as they focus on alternative options triggered by their desire of convenience (Colwell et al, 2008). In a mobile shopping platform convenience is mostly determined by the ease in accessing, searching and evaluating (Beauchamp and Ponder, 2010). During a mobile shopping journey consumers' can allegedly experience frustration due to overload of information, nonetheless a personalised content can offer a significant value for the customer by facilitating the process (Mahapatra, 2017; Kwon and Kim, 2012). More precisely, Seiders et al. (2007) stated that the personalised content offers the convenience that the consumer desires as accessing and researching the retailer's products is less complex and more targeted. Consumers feel more comfortable when precise information is provided to them which requires less searching and evaluating time for a desired product (Verhoef et al, 2007). A content based on customers' preferences minimize the effort needed for a customer to locate a product (Kwon and Kim, 2012). Personalised content also affects the transaction procedure, mainly referring to payments, which tend to be simpler and faster (Alicia et al, 2014). Therefore, personalised content can improve convenience as it reduces the time and effort of a purchase. Nevertheless, customers can be easily diverted from using a mobile application if the process still remains time-consuming and demands for a lot of cognitive and psychological effort due to malfunctions of the mobile app (Verhoef et al, 2007; Wu and Wang, 2006).

It is assumed that there is a positive relationship between convenience and personalised content (Mahapatra, 2017). Personalised content tends to facilitate the mobile shopping process as it speeds up the process and requires less cognitive and psychological effort (Kwon and Kim, 2012; Seiders et al, 2007). Therefore, based on the aforementioned analysis the following proposition arises.

Proposition 1: Consumers will feel more comfortable using a mobile application as personalised content positively 
influences convenience through reducing the time and effort required for the shopping experience.

\subsection{Personalised Content and M-Loyalty}

Customer m-loyalty signifies the customers' positive attitude towards a mobile retailer (Pratminingsih, Lipuringtyas and Rimenta, 2013). Customer m-loyalty is largely influenced by two main factors; satisfaction and trust. Research indicates that customer satisfaction is characterized as a key determinant of customer loyalty, as its effect is extremely significant (Pan, Sheng and Xie, 2012). Customer satisfaction refers to the customer's perception of an $\mathrm{m}$ - retailer; when the perception is affirmative, a consumer is satisfied and more willing to repurchase which can lead to loyalty (Shankar, Smith and Rangaswamy, 2003). Catalan (2013) stated that trust in the m-commerce environment consists a crucial antecedent for mobile shopping loyalty. Satisfaction plays a significant role in transforming customer's trust into loyalty (Horppu, Kuivalainen, Tarkiainen and Ellonen, 2008). Specifically, trust entails positive feelings between the two parties which can minimise any feelings of uncertainty and through increased satisfaction consumers become more confident to repeatedly use that mobile app, which consequently develops a loyal attitude (Razzaque and Boon, 2003; Deng et al, 2010).

In an m-platform, personalised content is considered an optimal marketing strategy to improve m-loyalty (Ligas, 2004). Quality is a key element for consumers to enjoy the experience of using the mobile app and feel satisfied (Smith and Reynolds, 2009). Low-quality on the other hand, leads to dissatisfaction and the consumer to opt for a different application (Pappas et al, 2014). For instance, it is reported that users seem confused when there is a vast amount of information which can cause dissatisfaction and subsequently switching to a different $\mathrm{m}$ - retailer. Pappas et al. (2012) argue that if the personalised content matches the consumers' preferences, it can lead to higher levels of consumer satisfaction. By providing personalized offers and recommendations, consumers tend to feel more satisfied as they are being supported on their decision-making process (Pappas et al, 2014). At this point, consumer satisfaction can have a positive impact on consumers' loyalty towards the m-retailer (Chang and Chen, 2009; Kwon and Kim, 2012).

At the same time, in the mobile environment, which is characterized for its uncertainty, due to the lack of physical presence and contact with experts and the products, trust is an essential condition for the participation of customers in m-commerce (Corbitt, Thanasankit and Yi, 2003). Understanding each customer's needs and preferences to implement a targeted and personalised strategy can contribute to higher levels of loyalty since it results in feeling satisfied and appreciated by the m-retailer (Nguyen and Mutum, 2012; Kalyanaramanm and Sundar, 2006; Limayem et al. 2000). For example, a 'goal-oriented shoppers' would benefit from a simple and well-structured mobile platform whereas an 'experiential shoppers' would appreciate a more amusing and visual mobile platform which allows them to interact with other members of that online community. Deploying such personalized marketing strategies is advisable to influence loyalty as that experience allows consumers to feel valued and thus, trust the company (Zhou et al, 2007). Research found that users of a mobile application who receive a personalised service trust that they will experience a valuable process since the content is related to their preferences (Ho, 2012).

However, it is essential to take into account that customers with higher levels of loyalty are more likely to feel betrayed (Grégoire et al, 2009). Overload of features and tailored information can make the consumer sceptical mostly when it is deducted from their private information (Chen et al, 2009; Xu et al, 2011). The violation of private data can be associated with damaging a company's trustworthiness and public image (Li et al. 2011; Pappas et al. 2012). According to research new consumers can also be reluctant in using a personalised shopping m-platform if they are asked to provide a wide range of information (Xia, 2002). Nonetheless, a study supports that the personalised-privacy paradox effects differently consumers based on their personality traits (Lee and Rha, 2016). In most cases the sense of satisfaction and trust strengthened by personalising the content, which drive consumer loyalty, seem to surpass any feeling of uncertainty (Pappas et al, 2014; Pappas et al, 2014; Chang and Chen, 2009).

It is indicated that personalised content can strengthen consumer loyalty. More precisely, through providing a customer-tailored content on a mobile application consumers tend to feel

more satisfied with the shopping experience (Papas et al, 2014) and build stronger trust bonds with a m-retailer (Nguyen and Mutum, 2012) which, consequently, promote greater consumers' loyalty towards the m-retailer (Razzaque and Boon, 2003; Deng et al, 2010). Subsequently, from all of the above discourse, the resulting proposition is generated.

Proposition 2: Through the provision of personalised content on mobile applications, consumers will become more loyal to a mobile retailer by experiencing greater satisfaction and stronger trust bonds with the m-retailer.

\subsection{The Role of Personalised Content on Purchase Intentions}

Extensive research has been conducted to determine what motivates customer's intent to purchase; two motivational triggers have been identified: utilitarian and hedonic motivations (Babin et al, 1994; Yang and Kim, 2012; Mahapatra, 2017; Papas et al, 2014; Anderson et al, 2014). "Utilitarian motivations relate to the functionality of shopping, while 
hedonic motivations are defined as consumers' enjoyment of the shopping experience itself' (Anderson et. al, 2014: $\mathrm{p}$. 774). O’Brien (2010) and Mikalef et al. (2013) stated that hedonic and utilitarian values during the shopping process are evident and will influence buying intentions in a positive way. Hedonic and utilitarian motivations co-exist in mobile shopping platforms as they can provide both the information consumers need to make an informed choice, which fulfil consumers' utilitarian values, and a more enjoyable and fun experience, which fulfil their hedonic values, through entrainment and interactivity functions (Sigala, 2006). In the m-commerce these triggers can be amplified through the use of personalised content (Yang and Kim, 2012).

Utilitarian motivation is linked with convenience as well as financial benefits (Kim and Hong, 2010). Personalized content enables consumers purchases by enhancing convenience in terms of time and effort on finding and purchasing the desired products (Kwon and Kim, 2012). More precisely, personalised recommendations and offers in consumers' busy daily lives is perceived as a unique treat which facilitates their evaluation and decision making process (Mahapatra, 2017; Zhang et al, 2012). Considering also the possible issues the mobile devices' screen size may instigate, a well-structured and convenient personalised layout would improve the shopping experience (Wang et al, 2015). In addition, personalising the transaction process makes the shopping experience even faster. These functions pose a sense of achievement through a valuable shopping experience (Mahapatra, 2017). Through convenient $\mathrm{m}-$ shopping, consumers find value which can increase their purchase intentions and the likelihood of future repurchases (Wang et al, 2015; Chiu et al, 2012). Personalised service, also, enhance customer loyalty (Kwon and Kim, 2012). When customers are loyal they build a bond with the retailer and create habits on which they depend on and halt to consider any alternatives (Wang et al, 2015). Enriched m-convenience through customised content mobile applications can increase purchase intentions for sceptical consumers who shop based on their habitual needs and desires (Wang et al, 2015). However, research shows that positive feelings need to be evident as well for the consumers to make a purchase (Papas, 2018), this posits that relying solely on trust, and thus loyalty, may not be sufficient. At this point, Fang et al. (2016) argue that by satisfying consumers' utilitarian values their emotional reactions are being affected as well; as the experience offers efficiency and a sense of achievement, they feel more fulfilled and happier. Nevertheless, during a shopping experience consumers' psychological state can be disrupted by an overload of information which would ultimately affect negatively their intention to purchase (Rose et al, 2012). Furthermore, it is of imperative importance to take into consideration the personalization-privacy paradox which could occur when customer need to decide whether privacy issues are more important than to fulfil their utilitarian values through personalisation (Baek, 2014). Such a concern creates negative feelings such as frustration and anxiety which could disturb their purchase intentions (Beaudry and Pinsonneault, 2010). Having considered that, research has shown that these feelings could be avoided with self-personalisation of content where consumers can provide only the information they desire and manage the recommendations they receive (Valenzuela et al. 2009).

Hedonic motivations correspond to the shopping experience which provokes positive feelings associated with the consumers' aspiration for fun, up-to-date information, discounts and the sense of escapism (Babin et al, 1994; Yang and Kim, 2012; Kwon and Kim, 2012; Li et al, 2012). Anderson et al (2014) support that consumers motivated by their hedonic values "enjoy the experience without the need to make a purchase, but a purchase is a result of the experience" (p. 774). For instance, through an interactive experience, like Augmented Reality, customers have the opportunity to experience an entertaining function while relaxing and trying on new available products on the market. It could be alleged that such an experience may fulfil their hedonic values but have no effect on purchase intention (Li et al, 2012). However, research shows that interactivity has positive influence on enjoyment and pleasure which eventually motivate consumers to continue with a purchase (Scholz and Duffy, 2018). According to a research conducted by Li and Yeh (2010) a mobile platform's design influences consumer trust since it can arouse a feeling of gratification. Through personalisation on the m-platform customers experience an emotional satisfaction and positive feelings like enjoyment which can drive to a purchase (Yang and Kim, 2012). It is also supported that consumers who are lead by their satisfaction, positive feelings and their trust tend to show greater willingness to make an impulsive purchase (Penz and Hogg, 2011) as well as future purchases (Wang and Liao, 2007). Nonetheless, when hedonic values are not met it can lead to negative emotional reactions which could drive customers away (Yang and Kim, 2012; Penz and Hogg, 2011). This is of paramount importance which denotes that the quality of the personalised content and functions has a pivotal effect on consumers' purchase of intentions ( $\mathrm{Li}$ et al, 2012).

The aforementioned analysis reflects the significance of personalised content to the formation of purchase intentions. Personalised content further assist consumers to fulfil both their utilitarian and hedonic motivations through optimising mobile application convenience (Kwon and Kim, 2012), enhancing m-loyalty (Kwon and Kim, 2012) and augmenting their emotions (Papas, 2018). For the previous analysis, proposition 5, presented below, is constructed.

Proposition 3: Personalised content through influencing the mobile applications' convenience, consumers' m-loyalty and their positive emotions will amplify mobile shopper's intentions to purchase. 


\section{Methodology and Data Analysis}

The main method of data collection was semi-structured interviews. Semi-structured interviews contain organised questions based on a specific area of research which can be furtherly elaborated during the interview process (Qu and Dumay, 2011). This ensures that the focus remains on the topic and covers a broad range of themes which help direct the interview to the topics that the researcher investigates (Qu and Dumay, 2011). Moreover, as interviews are based on human interaction, it allows the interviewer to have complete control of the interview (Qu and Dumay, 2011), ensuring that the researcher can determine the pace, style and order of the questions to provide worthy responses (Qu and Dumay, 2011). This type of interviews enables interviewees to answer the questions on a personal way, by expressing entirely their thoughts (Kvale and Brinkmann, 2009). The first few questions involved general information, while the rest were more detailed regarding emotions, opinions and experiences. More specifically, at first participants were asked general questions about their current relationship with the mobile applications and their relationship with cosmetic products and their purchases. Later on, questions became more in depth in terms of personalised content and beauty mobile applications concerning their shopping and behavioural attitude. During the interviews the conversations were recorded and later the recorded interviews were transcribed word by word.

\section{Findings}

\subsection{Proposition 1}

There was very strong supporting evidence by respondents highlighting the importance of convenience in terms of time when using a beauty mobile application. They emphasised on the perceived value of the beauty apps as they spent less time locating, evaluating and processing their desired products:

I like my beauty apps as they remember my payment detail and its more convenient and faster. (respondent 5)

So it makes it convenient and more comfortable and easy when changing products or adding new ones that can enhance the final look. (respondent 7)

Through personalised content most participants pointed out that the navigation is not only faster but simpler and easier as well as the levels of usability of these apps are higher. The personalised suggestions on products from the beauty applications enable them to locate new products without wasting any unnecessary effort:

The boots app stores individual data once you have created an account and keeps a record of the orders and the searches so that it offers options related to the once previously chosen. I love this! This is very convenient for me when searching for a product because I don't need to remember details and also offers the opportunity to obtain new products that are similar to old ones yet change a bit of your choices. (respondent 8)

I also like when the app can have straight access to my location status via my smartphone and as the result the app will be adjusted to the language and the availability (stock items) in the country I choose to use the app in. (respondent 2)

There was moderate evidence by the respondents supporting that they prefer to use a mobile beauty shopping application from another as it facilitates the process by reducing the cognitive and psychological effort and the time spent on their shopping experience:

I want an organised and easy to use app that offers many options and fast transaction process. I also want to be able to find products that suit me and be able to see an end result. I also prefer free apps that offer premium package with even more customised services even if it means paying a little extra. (respondent 7)

The study found very strong evidence suggesting that respondents enjoy using their mobile beauty applications as personalisation constitutes their mobile shopping experience more convenient since it requires less time and effort; therefore, the proposition has credibility.

\subsection{Proposition 2}

There was strong evidence from the respondents supporting that receiving personalised recommendations on their beauty apps lead to higher levels of satisfaction because they reflect their personal preferences and they feel that their choices are being understood and valued. There was strong evidence that respondents strengthen satisfaction is driven by the quality of their personalised content in terms of the organisation and layout, the vast amount of products and the available offers and discounts.

I am so much more satisfied now. Now the app is expressing part of me and although the app is used by lots of individuals it makes me feel unique... I always have recommended products and most importantly they give me discounts. (respondent 2)

I find it very satisfying as I can access everything I am looking for anytime, from wherever and very easily because I 
know exactly where to find them. Also I have access to a variety of products that it wouldn't be easy to find on my own. (respondent 6)

Even though most respondents feel satisfied by their personalised shopping experience, there were two respondents who expressed their scepticism towards the variety offered by a personalised beauty app:

Over all I believe that the idea of having profiles that saves your options is great. I also find the apps vey straight forward and easy to use. One problem is though that they lock on one look, but people need make ups for different occasions, so it would be nice to have this option as well without mixing the results. (respondent 7)

Additionally, there is strong evidence that respondents create trust bonds easier with companies that provide personalized content. However, there were three respondents who exclaimed some scepticism regarding their privacy and personalized content which affected negatively their trust:

I do not trust all beauty apps I have used. There were times that some apps had recommended to me products that I am sure I haven't used before with that retailer and this makes me very frustrated. (respondent 3)

Nonetheless, most respondents expressed that their trust on a mobile application is strengthened as they find that the benefits deriving from using personalised content are more significant. So, their trust is affected by how valuable they perceive the offered personalized content. Moderate supporting evidence denotes that specifically the recommendations and the design of the personalized content on their beauty app has a great affect on their trust towards an m-retailer.

It helps by making it more fun and it gives me the desire to enter the app and shop because through this app I always get target recommendations and I trust the app a lot now. (respondent 1)

There was moderate supporting evidence by respondents stating that their loyalty to a $\mathrm{m}$ - retailer is motivated by personalised discounts and offers:

When I buy products from these apps, I have an extra discount and some personalised offers for my next order, this makes me revisit the mobile app and search for extra products as well. (respondent 10)

There was moderate supporting evidence interlinking satisfaction stemmed by personalised recommendations, layout and financial benefits with strengthening consumer loyalty. The majority of the respondents also stated that through satisfying personalised recommendations and feeling valued, they trust their m-retailers and become more loyal to them:

I feel these apps know me and have earned my custom ... They make me feel satisfied with every purchase. I know the products will be great for me so that's why I always use the same apps. (respondent 5)

The ones I always use are because I am always satisfied with the products I receive and I trust the apps recommend the best products for me. (respondent 9)

Nevertheless, there was very strong supportive evidence suggesting that the respondents' loyalty on mobile beauty apps is influenced by the ease of usage offered by personalisation of m-platform. There was very strong supportive evidence stating that personalisation has ameliorated the ease of usage of these beauty apps influencing significantly their revisit of these apps:

How easy they are to use. The ones I use the most have easy navigation, with just some clicks I can access what I want and "try them on". If I like them very easily, I can press buy and they are mine. (respondent 11)

Responders emphasized that easy of usage of a mobile applications constitutes their experience for meaningful and less tiresome which significantly affects their loyalty to the m-retailer.

\subsection{Proposition 3}

There was strong evidence that respondents purchase intentions are driven by the need to complete a task with spending a less time and effort as possible. Most respondents supported that they are more motivated to make a purchase on beauty apps due to personalised features that are offered on the beauty apps. Respondents emphasised on the benefits of easy navigation, they can locate and buy related products to them without many "clicks, and fast payment on a purchase, as it makes their shopping experience more convenient:

I also find these apps vey straight forward and easy to use. I can just open the app using my smartphone find the targeted products, see what I like the most and just pay in few minutes. To be honest I don't really have much time to spend so it makes my life so much easier. (Respondent 3)

There was moderate evidence that respondents driven by their loyalty and habits of using the beauty apps, they will make future purchases. They supported that personalised content on beauty apps make the decision and evaluation process easier and efficient. Some respondents claimed that for their purchases they are using particular beauty apps, that they are satisfied with, because they offer a personalised content which they know represent their preferences and 
their mobile application's layout is organised in such a way that they can locate the desired products easier. There is also moderate evidence which support that as respondents feel trust for the beauty app, they will continue purchasing on the app as it appears as a habit and they perceive that m-retailers value them:

When I trust the company, I use it frequently and I'm more willing to buy more products. Beauty apps offer me the opportunity to have direct and quick access to a wide range of products and the world of beauty just by pressing a button on my smartphone screen. (Respondent 2)

There was strong evidence suggesting that respondents enjoy looking through their personalised recommendations that they end up spending more time on the mobile apps and personalised recommendations have an enjoyable experience with familiarising themselves the latest products which matches with their preferences, which leads to at least one purchase. Most respondents' purchase intentions are closely linked to the design of the beauty app and how satisfied they feel with it:

... But to be honest, I jsu enjoy so much to look through all the available recommended products to me and usually I end up spending too much time and too much money. This is not good for my purse! (respondent 6)

There is moderate supporting evidence suggesting that respondents purchase intentions are affected by the feeling of relaxation and the levels of escapism they experience on their mobile beauty apps:

In general, organised content makes me feel relaxed and at ease ... so It makes me likely to stay on the app for longer and explore more content and make a purchase in the end. (Respondent 5)

There was moderate supporting evidence that the quality of the personalised content is significant since when it fails to meet their expectations they experience negative feelings such as frustration. Some respondents argued that when such an occasion occurs they prefer to switch to another m-retailer:

The mobile app needs to be easy to use, and of great quality. If one doesn't have that I'm not going to use it...It really irritates I have many expectations and I demand a good service. (Respondent 11)

There was strong evidence that personalised discounts and offers influence positively the respondents' emotions and increase their intentions to purchase. Most respondents suggested that when they receive discounts and offers, they feel happier as they consider it, as a bargain, which persuades them to purchase more products. Moreover, respondents feel more fulfilled on their purchases as they considerate it as a great value for their money that are spending and thus they expressed higher willingness to repurchase for that m-retailer:

I always get triggered by the discounts that apps offer me... In the end actually, I spend the amount I wanted but I buy more things that most of the times I end up using quite a lot. This is so pleasing. (Respondent 10)

There was strong supporting evidence that AR creates an interactive environment that increases the purchases for respondents. Most respondents supported that through AR they undergo a fun and informative experience as they can try virtually the beauty products and play with the app. These respondents also experience higher levels of enjoinment and excitement. At the same time, most respondents acknowledge the strong benefits of AR as it helps them make informed choices and feel fulfilled. Therefore, most respondents as they experience positive emotions while using AR and it supports their evaluation process they always feel more willing to make a purchase:

MakeUp Genius by L'Oreal is very innovative and fun, it really takes the hustle of having to test each product in-store to actually see what suits you. I like that I can test foundations on my skin without actually having to apply it on and it really facilitates the purchasing experience. (Respondent 9)

There is strong evidence that respondents purchase of intentions is affected by the provision of personalised content. Through a personalised experience on the beauty applications they enjoy higher levels of convenience and loyalty and experience mostly positive emotions. Thus, the proposition has a credibility.

Nevertheless, there was very strong supporting evidence that privacy issues are highly influencing respondents purchases intentions. Most respondents claimed that they want to feel secure and protected when using personalised beauty apps. They are very concerned about their private data and how companies are using them:

Sometimes I feel distressed with all the personalised recommendations I receive because of all the recent issues with information leakage or inappropriate usage of private data. I try to limit the information I am sharing so when an app makes me feel like that I tend to stop using it. (respondent 4)

\section{Conclusions and Implications}

In this study all respondents' appreciation towards mobile beauty apps has risen as personalised content increases convenience throughout their shopping journey in terms of time and effort to locate, evaluate and process the products (Proposition 1). Secondly, respondents personalisation on their mobile applications beacme more loyal to m-retailer 
because it improves the ease of usage and their satisfaction and trust are higher (Proposition 2). Respondents through personalised recommendations and offers and higher quality of beauty applications feel more satisfied. In addition, the process of trusting a beauty application is facilitated by the perception of the value of personalised content. All these factors contribute to respondents build stronger loyalty towards an m-retailer. Lastly, all of these variables of consumer behavior seem to influence consumers' purchase intentions in relation with another. As personalised features seem to positively influence mobile convenience, $\mathrm{m}$ - loyalty and consumers' emotions it has been proven that through that influence personalisation on mobile beauty applications improves consumers' purchase intentions. From the findings of this study, there are numerous of managerial implications. First, convenience has a great impact on the use of a personalised mobile applications. This can be a valuable result for m-retailers as time and effort are important attributes of convenience and use it as competitive advantage. Managers should comprehend the value of time and effortfor users and provide them a service that satisfies these attributes and create an experience that matches with their preferences. For example, m-retailers could improve users' personalised experience through a real-time messaging with experts specialised on consumers products preferences. Specifically, a real-time communication could enable users on their shopping navigation as they will have a constant guide via messaging. Apart from convenience, m-retailers should focus on the levels of users m-loyalty. M-retailers should focus on the levels of satisfaction and trust of users to increase purchase intentions. Managers should embrace simplicity to avoid the overload information that drives the consumers away. Moreover, m-retailers should allow to users to change the content of the mobile application such as the layouts and size font to make it further personalised and satisfying. Moreover, trust is vital for consumer to use a mobile application. Therefore, $\mathrm{m}$ - retailers should focus on reducing the perceived risk that any privacy concerns could impose. For instance, they should have the privacy settings available for users to modify them in anytime. Moreover, reimbursement should be offered to users to guaranty the safety of their money. Lastly, managers should emphasise on the extent that emotions of consumers got triggered by feedback from users to improve their experience and emotional state. Positive emotions are linked to higher levels of purchase intentions; thus, managers should encourage users to make purchases on the mobile apps by providing them personalised offers and discounts. In addition, AR is a vital component for mobile applications, and especially for beauty apps, that triggers users' emotions. Therefore, m-retailers should focus on the quality of the functions to increase the interaction by creating a centric-user environment that users can feel unique, have fun and spend a more time on the mobile application.

\section{References}

Ahuja, V., \& Khazanchi, D. (2016). Creation of a Conceptual Model for Adoption of Mobile Apps for Shopping from E-Commerce Sites-An Indian Context' Procedia Computer Science, 91, 609-616. https://doi.org/10.1016/j.procs.2016.07.152

Alicia, I.-Y., María, P. M. R., \& Agustín, Á. H. (2014). 'What differentiates internet shoppers from internet surfers?', The Service Industries Journal, 34(6), 530-549. https://doi.org/10.1080/02642069.2014.871536

Babin, B. J., Darden, W. R., \& Griffin, M. (1994). Work and/or fun: measuring hedonic and utilitarian shopping values. Journal of Consumer Research, 20, 644-656. https://doi.org/10.1086/209376

Baek, Y. M. (2014). Solving the privacy paradox: a counter-argument experimental approach. Computers in Human Behaviour, 38, 33-42. https://doi.org/10.1016/j.chb.2014.05.006

Beauchamp, M. B., \& Ponder, N. (2010). Perceptions of retail convenience for in-store and online shoppers, The Marketing Management Journal, 20(1), 49-65.

Beaudry, A., \& Pinsonneault, A. (2010). The other side of acceptance: studying the direct and indirect effects of emotions on IT use' MIS Quarterly, 34(4), 689-710. https://doi.org/10.2307/25750701

Bellman, S., Potter, R. F., Treleaven-Hassard, S., Robinson, J. A., \& Varan, D. (2011). The effectiveness of branded mobile iphone apps. Journal of Interactive Marketing, 25, 191-200. https://doi.org/10.1016/j.intmar.2011.06.001

Berry, L. L., Seiders, K., \& Grewal, D. (2002). Understanding service convenience. The Journal of Marketing, 66(3), 1-17. https://doi.org/10.1509/jmkg.66.3.1.18505

Chang, H. H., \& Chen, S. W. (2009). Consumer perception of interface quality, security, and loyalty in electronic commerce' Information \& Management, 46(7), 411-417. https://doi.org/10.1016/j.im.2009.08.002

Chen, Y. C., Shang, R. A., \& Kao, C. Y. (2009). The effects of information overload on consumers subjective state towards buying decision in the internet shopping environment. Electronic Commerce Research and Applications, 8(1), 48-58. https://doi.org/10.1016/j.elerap.2008.09.001

Chiu, C. M., Wang, E. T., Fang, Y. H., \& Huang, H. Y. (2014). Understanding customers' repeat purchase intentions in B2C e-commerce: the roles of utilitarian value, hedonic value and perceived risk. Information Systems Journal, 24(1), 85-114. https://doi.org/10.1111/j.1365-2575.2012.00407.x 
Colwell, S. R., Aung, M., Kanetkar, V., \& Holden, A. L. (2008). Toward a measure of service convenience: multiple-item scale development and empirical test. Journal of Services Marketing, 22(2), 160-169. https://doi.org/10.1108/08876040810862895

Copeland, M. T. (1923). Relation of consumers' buying habits to marketing methods. Harvard business review, 1(2), 282-289.

Corbitt, B. J., Thanasankit, T., \& Yi, H. (2003). Trust and e-commerce: a study of consumer perceptions. Electronic commerce research and applications, 2(3), 203-215. https://doi.org/10.1016/S1567-4223(03)00024-3

Deng, Z., Lu, Y., Wei, K. K., \& Zhang, J. (2010). Understanding customer satisfaction and loyalty: An empirical study of mobile instant messages in China. International journal of information management, 30(4), 289-300. https://doi.org/10.1016/j.ijinfomgt.2009.10.001

Devaraj, S., Fan, M., \& Kohli, R. (2003). E-loyalty: elusive ideal or competitive edge?. Communications of the ACM, 46(9), 184-191. https://doi.org/10.1145/903893.903936

Du Plessis, C. (2017). Mobile marketing: building blocks for mobile content marketing to add value and relevance for mobile users. Communitas, 22, 31-47. https://doi.org/10.18820/24150525/Comm.v22.3

Fang, J., George, B., Shao, Y., \& Wen, C. (2016). Affective and cognitive factors influencing repeat buying in e-commerce. Electronic Commerce Research and Applications, 19, 44-55. https://doi.org/10.1016/j.elerap.2016.08.001

Grégoire, Y., Tripp, T. M., \& Legoux, R. (2009). When customer love turns into lasting hate: The effects of relationship strength and time on customer revenge and avoidance. Journal of marketing, 73(6), 18-32. https://doi.org/10.1509/jmkg.73.6.18

Horppu, M., Kuivalainen, O., Tarkiainen, A., \& Ellonen, H. K. (2008). Online satisfaction, trust and loyalty, and the impact of the offline parent brand. Journal of Product \& Brand Management, 17(6), 403-413. https://doi.org/10.1108/10610420810904149

Hosany, S., \& Martin, D. (2012). Self-image congruence in consumer behavior. Journal of Business Research, 65(5), 685-691. https://doi.org/10.1016/j.jbusres.2011.03.015

Jiang, L., Yang, Z., \& Jun, M. (2013). Measuring consumer perceptions of online shopping convenience. Journal of Service Management, 24(2), 191-214. https://doi.org/10.1108/09564231311323962

Kalyanaraman, S., \& Sundar, S. S. (2006). The psychological appeal of personalized content in web portals: does customization affect attitudes and behavior?. Journal of Communication, 56(1), 110-132. https://doi.org/10.1111/j.1460-2466.2006.00006.x

Kim, E., Lin, J. S., \& Sung, Y. (2013). To app or not to app: Engaging consumers via branded mobile apps. Journal of Interactive Advertising, 13(1), 53-65. https://doi.org/10.1080/15252019.2013.782780

Kvale, S., \& Brinkmann, S. (2009), Inter Views: Learning the Craft of Qualitative Research Interviewing, Sage, Los Angeles, CA.

Kwon, K., \& Kim, C. (2012). How to design personalization in a context of customer retention: Who personalizes what and to what extent?. Electronic Commerce Research and Applications, 11(2), 101-116. https://doi.org/10.1016/j.elerap.2011.05.002

Lee, J. M., \& Rha, J. Y. (2016). Personalization-privacy paradox and consumer conflict with the use of location-based mobile commerce. Computers in Human Behavior, 63, 453-462. https://doi.org/10.1016/j.chb.2016.05.056

Li, Y. M., \& Yeh, Y. S. (2010). Increasing trust in mobile commerce through design aesthetics. Computers in Human Behavior, 26(4), 673-684. https://doi.org/10.1016/j.chb.2010.01.004

Ligas, M. (2004). Personalizing services encounters: the role of service provider actions in developing customer trust. Services marketing quarterly, 25(4), 33-51. https://doi.org/10.1300/J396v25n04_03

Limayem, M., Khalifa, M., \& Frini, A. (2000). What makes consumers buy from Internet? A longitudinal study of online shopping. IEEE Transactions on systems, man, and Cybernetics-Part A: Systems and Humans, 30(4), 421-432. https://doi.org/10.1109/3468.852436

Linton, H. (2015). The mobile revolution is here: are you ready?.

Mahapatra, S. (2017). Mobile shopping among young consumers: an empirical study in an emerging market. International Journal of Retail \& Distribution Management, 45(9), 930-949. https://doi.org/10.1108/IJRDM-08-2016-0128

Mahatanankoon, P., Wen, H. J., \& Lim, B. (2005). Consumer-based m-commerce: exploring consumer perception of mobile applications. Computer standards \& interfaces, 27(4), 347-357. https://doi.org/10.1016/j.csi.2004.10.003

Montgomery, A. L., \& Smith, M. D. (2009). Prospects for personalization on the internet. Journal of Interactive Marketing, 23(2), 130-137. https://doi.org/10.1016/j.intmar.2009.02.001

Nguyen, B., \& Mutum, D. S. (2012). A review of customer relationship management: successes, advances, pitfalls and 
futures. Business Process Management Journal, 18(3), 400-419. https://doi.org/10.1108/14637151211232614

O'Brien, H. L. (2010). The influence of hedonic and utilitarian motivateons on user engagement: the case of online shopping experiences. Interacting with Computers, 22(5), 344-352. https://doi.org/10.1016/j.intcom.2010.04.001

Ono, A., Nakamura, A., Okuno, A., \& Sumikawa, M. (2012). Consumer Motivations in Browsing Online Stores Mobile Devices. International Journal of Electronic Commerce, $6(4), \quad 153-178$. https://doi.org/10.2753/JEC1086-4415160406

Pappas, I. O., Giannakos, M. N., \& Chrissikopoulos, V. (2012). Personalized services in online shopping: Enjoyment and privacy. In Information Society (i-Society), 2012 International Conference on, 168-173.

Pappas, I., Kourouthanassis, P., Giannakos, M., \& Chrissikopoulos, V. (2014). Shiny happy people buying: the role of emotions on personalized e-shopping. Electronic Markets, 24(3), $193-206$. https://doi.org/10.1007/s12525-014-0153-y

Parise, S., Guinan, P. J., \& Kafka, R. (2016). Solving the crisis of immediacy: How digital technology can transform the customer experience. Business Horizons, 59(4), 411-420. https://doi.org/10.1016/j.bushor.2016.03.004

Penz, E., \& Hogg, M. K. (2011). The role of mixed emotions in consumer behaviour: Investigating ambivalence in consumers' experiences of approach-avoidance conflicts in online and offline settings. European Journal of Marketing, 45(1/2), 104-132. https://doi.org/10.1108/03090561111095612

Pratminingsih, S. A., Lipuringtyas, C., \& Rimenta, T. (2013). Factors influencing customer loyalty toward online shopping. International Journal of Trade, Economics and Finance, 4(3), 104-110. https://doi.org/10.7763/IJTEF.2013.V4.268

Qu, S., \& Dumay, J. (2011). The qualitative research interviews. Qualitative Research in Accounting \& Management, 8(3), 238-264. https://doi.org/10.1108/11766091111162070

Razzaque, M. A., \& Boon, T. G. (2003). Effects of dependence and trust on channel satisfaction, commitment and cooperation. Journal of Business to Business marketing, 10(4), 23-48. https://doi.org/10.1300/J033v10n04_02

Ricotta, F., \& Costabile, M. (2007). Customizing customization: A conceptual framework for interactive personalization. Journal of interactive marketing, 21(2), 6-25. https://doi.org/10.1300/J033v10n04_02

Rose, S., Clark, M., Samouel, P., \& Hair, N. (2012). Online customer experience in e-retailing: an empirical model of antecedents and outcomes. Journal of Retailing, 88(2), 308-322. https://doi.org/10.1016/j.jretai.2012.03.001

Scholz, J., \& Duffy, K. (2018). We ARe at home: How augmented reality reshapes mobile marketing and consumer-brand relationships. Journal of Retailing and Consumer Services, 44, 11-23. https://doi.org/10.1016/j.jretconser.2018.05.004

Seiders, K., Voss, G. B., Godfrey, A. L., \& Grewal, D. (2007). SERVCON: development and validation of a multidimensional service convenience scale. Journal of the academy of Marketing Science, 35(1), 144-156. https://doi.org/10.1007/s11747-006-0001-5

Shankar, V., \& Balasubramanian, S. (2009). Mobile marketing: a synthesis and prognosis. Journal of interactive marketing, 23(2), 118-129. https://doi.org/10.1016/j.intmar.2009.02.002

Shankar, V., Kleijnen, M., Ramanathan, S., Rizley, R., Holland, S., \& Morrissey, S. (2016). Mobile shopper marketing: Key issues, current insights, and future research avenues. Journal of Interactive Marketing, 34, 37-48. https://doi.org/10.1016/j.intmar.2016.03.002

Shankar, V., Smith, A. K., \& Rangaswamy, A. (2003). Customer satisfaction and loyalty in online and offline environments. International journal of research in marketing, 20(2), 153-175. https://doi.org/10.1016/S0167-8116(03)00016-8

Shankar, V., Venkatesh, A., Hofacker, C., \& Naik, P. (2010). Mobile marketing in the retailing environment: current insights and future research avenues. Journal of interactive marketing, 24(2), 111-120. https://doi.org/10.1016/j.intmar.2010.02.006

Sigala, M., \& Christou, E. (2006). Mass customisation implementation models and customer value in mobile phones services. Managing Service Quality: An International Journal. https://doi.org/10.1108/09604520610675720

Smith, A., \& Reynolds, N. (2009). Affect and cognition as predictors of behavioral intentions towards services. International Marketing Review, 26(6), 580-600. https://doi.org/10.1108/02651330911001305

Szutowski, D., \& Szułczyńska, J. (2016). PRODUCT INNOVATION IN COSMETIC INDUSTRY-CASE STUDY OF MAJOR COSMETIC COMPANIES. In SOCIAL RELATIONS AND CONFLICTS IN CONDITIONS OF INTENSIFICATION OF ECONOMIC PROCESSES AND DOMINANCE OF LIBERAL IDEOLOGY (pp. 20-21). https://doi.org/10.18007/gisap:ejm.v0i12.1620

Valenzuela, A., Dhar, R., \& Zettelmeyer, F. (2009). Contingent response to self-customization procedures: Implications for decision satisfaction and choice. Journal of Marketing Research, 46(6), 754-763. https://doi.org/10.1509/jmkr.46.6.754 
Verhoef, P. C., Neslin, S. A., \& Vroomen, B. (2007). Multichannel customer management: Understanding the research-shopper phenomenon. International journal of research in marketing, 24(2), 129-148. https://doi.org/10.1016/j.ijresmar.2006.11.002

Wang, Y. S., \& Liao, Y. W. (2007). The conceptualization and measurement of m-commerce user satisfaction. Computers in human behavior, 23(1), 381-398. https://doi.org/10.1016/j.chb.2004.10.017

WARC. (2015). 'Mobile apps are the future of media', WARC online, (Retrieved from) www.warc.com/mobile-apps-are-the-future-of-media/ [Accessed 28th Oct 2018]

WARC. (2017). '5.5bn people will use mobile devices by 2022', WARC online,(Retrievedfrom)https://www.warc.com/NewsAndOpinion/News/5.5bn_people_wil 1_use_mobile_devices_by_2022/39021 [Accessed 20th Oct 2018]

Wu, J. H., \& Wang, S. C. (2005). What drives mobile commerce?: An empirical evaluation of the revised technology acceptance model. Information \& management, 42(5), 719-729. https://doi.org/10.1016/j.im.2004.07.001

Xia, L. (2002). Affect as information: the role of affect in consumer online behaviors. ACR North American Advances.

Yang, K., \& Kim, H. Y. (2012). Mobile shopping motivation: an application of multiple discriminant analysis. International Journal of Retail \& Distribution Management, 40(10), 778-789. https://doi.org/10.1108/09590551211263182

Zhang, H., Lu, Y., Shi, X., Tang, Z., \& Zhao, Z. (2012). Mood and social presence on consumer purchase behaviour in C2C E-commerce in Chinese culture. Electronic Markets, 22(3), $143-154$. https://doi.org/10.1007/s12525-012-0097-z

Zhou, F., Ji, Y., \& Jiao, R. J. (2013). Affective and cognitive design for mass personalization: status and prospect. Journal of Intelligent Manufacturing, 24(5), 1047-1069. https://doi.org/10.1007/s10845-012-0673-2

\section{Copyrights}

Copyright for this article is retained by the author(s), with first publication rights granted to the journal.

This is an open-access article distributed under the terms and conditions of the Creative Commons Attribution license which permits unrestricted use, distribution, and reproduction in any medium, provided the original work is properly cited. 